Research Article

\title{
Optimal Fixed Route for Multimodal Transportation of Vehicle Logistics in Context of Soft Time Windows
}

\author{
Wanying Zhao \\ Institute of Logistics Science \& Engineering, Shanghai Maritime University, Shanghai, China \\ Correspondence should be addressed to Wanying Zhao; wyzhao@shmtu.edu.cn
}

Received 20 April 2021; Accepted 13 July 2021; Published 26 July 2021

Academic Editor: Lu Zhen

Copyright (c) 2021 Wanying Zhao. This is an open access article distributed under the Creative Commons Attribution License, which permits unrestricted use, distribution, and reproduction in any medium, provided the original work is properly cited.

In order to improve customer satisfaction and reduce the cost of vehicle logistics transportation, this paper adopts the mixedinteger programming model to analyze the delivery routes of vehicle logistics and make simulation and analysis based on the real delivery case. The results show that, compared with a single transportation scheme, the vehicle logistics optimization scheme based on the mixed-integer programming model is able to produce the optimal multimodal transportation plan, which can reduce the transportation costs, improve the service of transportation enterprises, and enhance their core competitiveness.

\section{Introduction}

The data of 2020 China automobile production and sales released by the China Association of Automobile Manufacturers on January 13, 2021, showed that production volume in 2020 stood at 25.225 million vehicles and sales volume at 25.311 million. All the automobiles produced and sold by China throughout the year are transported through vehicle logistics (VL). Based on the agile automotive supply chain environment focusing on time competition, vehicle logistics is to make quick response and punctual delivery by the object of vehicle logistics, which meets the requirements for delivery time, delivery place, and quality assurance according to customer order. Vehicle logistics has evolved from simple cargo movement to a new type of logistics featured by transportation-dominance, warehousing, distribution, and end-user value-added services as supplementary parts.

The newly issued regulation "Limits of dimensions, axle and mass for motor vehicles, trailers and combination vehicles (GB1589-2016)," as one of the most fundamentals in automobile standards, exerts an important influence on automobile transportation, traffic management, logistics transportation, playing a vital leading role in the development of automobiles. The standard limits the length of the central axle trailer loaded with the whole vehicle to 22 meters, the width to 2.55 meters, and the height to 4 meters, and loading more than 8 vehicles at one time is not allowed. In the case of unchanged freight rates, compared with the original large pallet trucks carrying more than a dozen trucks at the same time, this regulation cuts off the profits of the transportation company by a large margin, which brought a major blow to the vehicle transportation company.

Vehicle logistics is comprised of land transport, water transport, air transport, and so forth. Land transport can be divided into highway transport and railway transport while water vehicle logistics can be applied to container-vehicle logistics and roll-on roll-off VL. As for truck logistics companies, the optimization of distribution routes in the context of time windows, the selection of optimized routes from the road transportation, and water transportation and railway transportation are the focus of this study. This study attempts to find ways to effectively reduce the logistic costs of automobile manufacture by the use of mass, low-cost water transport, and railway transport, by which companies can improve their service and efficiency and enhance their core competitiveness. As a result, the optimal transportation mode based on the model of the vehicle operation of fixed 
routes is significant to improve the operation and management of automobile logistics enterprises.

Generally, the problem of vehicle logistics in the context of time windows refers to the handling approaches in reaction to the requirements for vehicle's arrival time, service time, and subsequent noncompliance.

There are two scenarios of vehicle logistics in the context of hard time windows: if the customer requires that the vehicle arrives at the earliest or the deadline time, the vehicle begins to provide service after the arrival of the vehicle within the time window and the service time upon completion shall not exceed the specified deadline. If there is noncompliance, that service will be flatly declined or refused. And such a problem is called vehicle logistics with a hard time window. The second scenario is that the customer requires the vehicle to arrive within the specified early and late time, including the earliest time prior to the ready-toserve time and the late time of arrival later than the ready-toserve time. In the context of early arrival, the vehicles have to wait for the service till the specified time. In the context of late arrival, that service will be flatly declined or refused. Such a problem is also referred to as vehicle logistics in the context of hard time windows.

As such, the problems of the vehicle logistics in the context of soft time windows are more complex, including the direct loss of profit caused by nonpunctual demand requirements and the indirect customer loss caused by declined customer satisfaction. However, rich experience and continuous practice verification are needed to calculate these loss costs. And there are three specific scenarios with respect to the time window: first, if the vehicle arrives within the time window, but subsequent to completion of service, the time exceeds the latest service acceptance time in the customer-specified time window. In this case, service is still allowed, but it may be affected when the vehicle reaches the next node. Secondly, if the vehicle arrives prior to the earliest service acceptance time under the time window, the customer will accept the service, but a penalty cost is added for the vehicle's early arrival. In the last case, if the vehicle arrives later than the deadline service time of the time window, the customer not only accepts the service but also adds a penalty for the vehicle's late arrival.

A host of scholars have researched the optimization of vehicle routing of vehicle logistics in the context of time windows from different perspectives. Normasari [1] formulated the mathematical model of the CGVRP and propose simulated annealing (SA) heuristic for its solution in which the CGVRP is set up as a mixed-integer linear program (MILP). Li and Fu [2] proposed a two-layer order allocation model for order allocation in vehicle logistics service supply chain, considering the multiple transportation modes. With the principle of cost minimization, $\mathrm{Hu}$ and Yuhong [3] started from route optimization and determined the multimodal transportation scheme within the limitation of time. Jiang et al. [4] put forward the vehicle logistics route optimization network in terms of the two resources, the distribution centers of shared vehicles and shared vehicles, respectively; constructed a mathematical optimization model aiming to minimize the total cost of vehicle logistics transportation; and developed a heuristic algorithm based on genetic algorithm. Cordeau et al. [5] designed a rolling horizon algorithm to dynamically dispatch road transport vehicles in response to the uncertainty of delivery and achieved the goal of minimizing transport vehicle costs. Hou et al. [6] constructed an optimal route for vehicle logistics distribution by using an adaptive genetic algorithm. Dell'Amico et al. [7] verified the search algorithm for the loading of auto-carrier transportation and optimal selection route. Liu and $\mathrm{Ma}$ [8] analyzed the plan for vehicle leasing and vehicle sharing within the range of time windows. Cheng et al. [9] raised an improved genetic annealing algorithm to optimize transportation with an adaptive crossvariance rate strategy. Ma et al. [10] analyzed the issue of time-dependent vehicle running speed in practice and studied the solution of time-dependent vehicle routing. Liu et al. [11] studied vehicle routing under sudden-onset disasters. Baldacci [12] established a cost model on the optimization of the vehicle logistics network, used heuristic algorithm and exact algorithm to solve the problem, and found that the heuristic algorithm for multinode network optimization problem can obtain an effective solution in a short time. Xiong et al. [13] analyzed the optimization of multimodal transportation and multiagent operation in the context of time windows. Ceschia et al. [14] designed a tabu exploration algorithm for the heterogeneous vehicle routing problem in the context of time windows. Lin et al. [15] improved the ant colony algorithm for the vehicle routing problem with time windows. Jin et al. [16] used a piecewise linear pricing mechanism to establish a piecewise linear model, taking into account the impact of the difference in price discounts of different railway transportation volumes on the structure of the vehicle distribution network.

From the literature review mentioned above, it is apparent that scholars at home and abroad have made some achievements in the vehicle routing problem in the context of time window, but the research on vehicle logistics optimization in terms of multimodal transportation is insufficient yet. Most of the studies only take into consideration the objective function of minimizing transportation costs but fail to consider the problem of time constraints. As to vehicle logistics, we believe that it is inadequate to consider the only factor of the transportation route optimization; instead, it may be more sensible to choose a reasonable multimodal transport scheme according to the real situation. This study focuses on vehicle logistics optimization of multimodal transportation in the context of time window, which is a complement and improvement compared with previous research, as it takes customers' demand into account and enriches the results of vehicle logistics transportation reoptimization.

In this study, we explore the distribution optimization problem of vehicle logistics in the context of transport time limit. It establishes a mathematical model based on the goal, to make the transportation cost optimization as low as possible, and develops an optimal solution to the vehicle logistics multimodal transport while leveraging the CPLEX (Branch and Bound Algorithm) to precede the model. Real 
cases prove that the route solution is effective in solving the practical problems of transportation enterprises.

\section{Problem Descriptions and Modeling}

2.1. Problem Description. Vehicle logistics in the context of time windows provides customers in different cities with the quantity of vehicles they need to purchase. The logistics and transportation company dispatches vehicles from OEMs to meet customer needs. Generally, customers have requirements for vehicle arrival time, that is, time window. The paper considers an OEM, multiple demand points, and the demand and time windows of each demand point. The specific situation is as follows.

Every city generally has a demand for vehicles from the original equipment manufacturer (OEM) to the destination city via multiple cities. The vehicle logistics network composed of the OEM, transit cities, and destination cities is shown in Figure 1. Every city has different requirements for vehicles. The vehicle logistics from OEM to other cities may bypass highway, railway, or water transportation. If transporting vehicles satisfies the requirements of cities along the route and destination cities, it is necessary to consider the cost of transshipment between cities and the time limit incurred by each city. If overtime occurs, there will be delay costs. It is essential to choose the optimized transportation route as a whole.

2.2. Model Hypothesis. There is one and only one mode of transportation for each distance travelled. There are sufficient means of transport; that is, each mode of transport that is selected for each distance can cover the whole distance without resorting to other modes, not considering the round trip.

Use the mixed integer programming model for calculations.

\subsection{Model Parameters and Definitions}

$o$ : point of departure

$i$ : the $i^{\text {th }}$ supply point, which is the $i^{\text {th }}$ distance travelled corresponding to the supply point

$d_{i}$ : the demand at the $i^{\text {th }}$ supply point

$t_{i}^{s}$ : the $s^{\text {th }}$ transportation time of the $i^{\text {th }}$ distance travelled

$c_{i}^{s}$ : the unit transportation cost of the $s^{\text {th }}$ transportation mode on the $i^{\text {th }}$ distance travelled (unit: per vehicle)

$t t_{s h}^{i}$ : the transit time of the $i^{\text {th }}$ supply points and for the $s, h$ transportation ways

$c t_{s h}^{i}$ : the unit transfer cost of the $i^{\text {th }}$ supply point and $s, h$ two modes of transport (yuan/(per vehicle per kilometer))

$p p_{i}$ : time limit for the $i^{\text {th }}$ supply point

$c s_{i}$ : overtime unit cost of the $i^{\text {th }}$ supply point (yuan/ vehicle)

$p_{i}=\sum_{j=i}^{n} d_{i}$ : the $i^{\text {th }}$ transportation volume

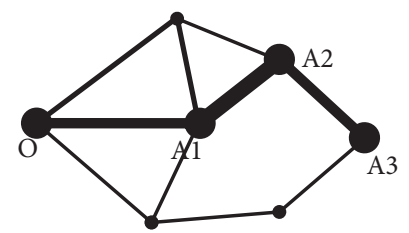

Figure 1: The vehicle logistics network.

$q_{i}=\sum_{j=i+1}^{n} d_{i}: \quad$ the $i^{\text {th }}$ node transfer volume $(1 \leq i \leq n-1)$

Decision variables:

$x_{i}^{s}$ : 0 -1 variables, whether the $\mathrm{i}^{\text {th }}$ distance travelled is the $s$ transportation mode; 1 is yes and 0 is no

$y_{s h}^{i}: 0-1$, whether the $i^{\text {th }}$ supply point is $s, h$ for transshipment; 1 is yes and 0 is no

$T_{i}$ : arrival time of the $i^{\text {th }}$ supply point

$w_{i}$ : delay time of the $i^{\text {th }}$ supply point

$y_{i}: 0-1$ variable, whether the $i^{\text {th }}$ supply point is delayed;

1 is yes and 0 is no

\subsection{Mathematical Formulation.}

$$
\min \sum_{s=1}^{3} \sum_{i=1}^{n} c_{i}^{s} p_{i} x_{i}^{s}+\sum_{h=1}^{3} \sum_{s=1}^{3} \sum_{i=1}^{n} c t_{s h}^{i} q_{i} t t_{s h}^{i} y_{s h}^{i}+\sum_{i=1}^{n} c s_{i} w_{i} .
$$

Minimize the total cost, including transportation cost, transshipment cost, and delay cost:

$$
\sum_{s=1}^{3} x_{i}^{s}=1, \quad i=1, \ldots, n .
$$

Choose one and only one mode of transportation for the distance travelled:

$$
x_{i}^{s} \leq \sum_{h=1}^{3} y_{s h}^{i}, \quad i=1, \ldots, n-1,
$$

$$
x_{i+1}^{s} \leq \sum_{h=1}^{3} y_{h s}^{i}, \quad i=1, \ldots, n-1,
$$

$$
\sum_{h=1}^{3} \sum_{s=1}^{3} y_{s h}^{i}=1, \quad i=1, \ldots, n-1 .
$$

Transshipment is required if the transportation mode at both ends of the supply point (3)-(5) is different:

$$
\begin{aligned}
& T_{i}= \begin{cases}\sum_{s=1}^{3} t_{1}^{s} x_{1}^{s}, & i=1, \\
\sum_{s=1}^{3} \sum_{j=1}^{i} t_{j}^{s} x_{j}^{s}+\sum_{h=1}^{3} \sum_{s=1}^{3} t t_{s h}^{i-1} y_{s h}^{i-1}, & 2 \leq i \leq n,\end{cases} \\
& T_{i}-p p_{i} \leq M y s_{i}, \quad i=1, \ldots, n, \\
& w_{i}-\left(T_{i}-p p_{i}\right) \leq M\left(y s_{i}-1\right), \quad i=1, \ldots, n,
\end{aligned}
$$




$$
\begin{aligned}
& x_{i}^{s} \in\{0,1\}, \quad i=1, \ldots, n, s=1,2,3, \\
& y_{s h}^{i} \in\{0,1\}, \quad i=1, \ldots, n-1, s, h=1,2,3, \\
& y_{i} \in\{0,1\}, \quad i=1, \ldots, n .
\end{aligned}
$$

Whether the arrival at the supply points (7) and (8) is delayed: if it is delayed, calculate the delay time.

\section{Case Analyses}

A company needs to send vehicles from the Shanghai car factory to Tianjin, Beijing, and Dalian every month. At the same time, the time limit of vehicles' arrival is required to meet customer's demand for orders. The transport from Shanghai to Beijing transits at Tianjin, and the transport from Shanghai to Dalian transits at Tianjin and Beijing. The car factory uses KPI to access the performance of the time limit of the transport company. KPI includes vehicle damage rate, on-time delivery rate, on-time arrival rate, and data accuracy. In this simulation, on-time arrival rate, part of the $\mathrm{KPI}$ is converted into penalty costs.

3.1. Data of the Car of a Certain Brand Sent from Shanghai to Tianjin, Beijing, and Dalian. The demand for the car of brand A in Tianjin, Beijing, and Dalian is D1, D2, and D3, respectively:

$$
\begin{aligned}
& D 1=966 ; \\
& D 2=3855 \\
& D 3=121
\end{aligned}
$$

See Table 1 for the transportation time rate from Shanghai to Tianjin, Tianjin to Beijing, Beijing to Dalian, Shanghai to Beijing, and Shanghai to Dalian.

The unit transportation cost of Shanghai to Tianjin, Tianjin to Beijing, Beijing to Dalian, Shanghai to Beijing, and Shanghai to Dalian is shown in Table 2.

The transit time in Tianjin and Beijing when transporting vehicles from Shanghai to Tianjin and Beijing is shown in Table 3.

The unit transshipment costs per two modes of transport for vehicles departing from Shanghai via Tianjin and Beijing are shown in Table 4.

The arrival time limit of transport vehicles departing from Shanghai to Tianjin, Beijing, and Dalian (due date) is shown in Table 5.

Penalty for arriving at the destination city for one hour overtime: RMB 10/vehicle $\left(c s_{i}\right)$.

The vehicle transport volume from Shanghai to Tianjin, Beijing, and Dalian is 4942, 3976, and 121, respectively, $p_{i}=\sum_{j=i}^{n} d_{i}$.

The transport volume in Tianjin and Beijing is 3976 and 121. respectively. $\left(q_{i}=\sum_{j=i+1}^{n} d_{i}\right)$.
3.2. Computational Results. For road transportation time, we have calculated the effective transportation time, and the sleep time of the driver is not considered. The calculation results with cplex_studio125.win-x86-32 are as follows:

Using the data provided, the Shanghai-Tianjin waterway unit transportation cost 600 is the lowest, while the Shanghai-Tianjin section uses water transportation, and the Tianjin-Beijing and Beijing-Dalian sections use railway transportation, which has the lowest cost.

There will be transshipment charges in Tianjin.

As the transit time from Tianjin waterway to railway is waiting for the train for 3-48 hours, the calculation was carried out in three cases:

(1) Transshipment takes 3 hours:

Therefore, if the transshipment in Tianjin is not overtime, the lengths of time to reach Tianjin, Beijing, and Dalian are 48, 52, and 58 hours, respectively. The total cost is $3,847,300,300$ yuan.

(2) Transshipment takes 24 hours:

Therefore, if the transshipment in Tianjin is not overtime, the lengths of time to reach Tianjin, Beijing, and Dalian are 48, 73, and 79 hours, respectively. The total cost is $3,947,508,800$ yuan.

(3) Transshipment takes 48 hours:

Therefore, the transshipment in Tianjin will be overtime in Beijing, and the lengths of time to reach Tianjin, Beijing, and Dalian are 48, 97, and 103 hours respectively, and the overtime cost for 1 hour in Beijing is 38550 yuan. The total cost is $4,105,676$ million yuan.

Based on the above results, the analysis and discussion are as follows.

In terms of other transportation modes, for example, in the first case, direct transportation from Shanghai to Beijing, the other two multimodal transportation routes are unchanged, and the longest transmit time from Tianjin waterway to railway is 48 hours. The minimum cost of direct transportation from Shanghai to Beijing is 3.084 million yuan for railway transportation. The demand for Beijing in the model is changed to 0 , and the transportation mode remains unchanged. The multimodal transportation cost is $75,596,960$ yuan, and the total logistics cost is $3,839,696$ yuan. In the second case, direct transportation from Shanghai to Dalian and multimodal transportation in the other two places, we can get to know that there is no change in the first two sections of the transportation mode. A direct railway transport from Shanghai to Dalian and the minimum total logistics cost is 405.7298 yuan. In the third case, the three places all adopt the mode is direct transportation. Obviously, the total freight rate is the lowest at 3,784,600 yuan, if we take the water transport from Shanghai to Tianjin and Dalian and the railway from Shanghai to Beijing.

From the above analysis, it is noticeable that the cost of direct transportation is the lowest; thus, this mode is highly recommended. But this is the result according to data 
TABle 1: Transportation time of each distance (unit: hours).

\begin{tabular}{|c|c|c|c|}
\hline$t_{i}^{s}$ & Road transportation time & Railway transportation time (hours) & Waterway transportation time \\
\hline Shanghai to Tianjin & 16 hours +8 sleep hours & 6 & 48 hours \\
\hline Tianjin to Beijing & 2 hours & 1 & N/A \\
\hline Beijing to Dalian & 12 hours +8 sleep hours & 6 & $\mathrm{~N} / \mathrm{A}$ \\
\hline Shanghai to Beijing & 18 hours +8 sleep hours & 6 & N/A \\
\hline Shanghai to Dalian & 30 hours +16 sleep hours & 11 & 48 hours \\
\hline
\end{tabular}

TABLE 2: Unit transportation cost of each route (unit: CNY/vehicle).

\begin{tabular}{lccc}
\hline$c_{i}^{s}$ & Highway unit cost & Railway unit cost & Waterway unit cost \\
\hline Shanghai to Tianjin & 1500 & 700 & 600 \\
Tianjin to Beijing & 350 & 200 & N/A \\
Beijing to Dalian & 1000 & 600 & N/A \\
Shanghai to Beijing & 1700 & 800 & N/A \\
Shanghai to Dalian & 2400 & 1100 & 1000 \\
\hline
\end{tabular}

TABle 3: Transit time of two transport modes at each point (unit: hours).

\begin{tabular}{lccc}
\hline$t t_{s h}^{i}$ & Transit time of highway to waterway & Transit time of waterway to railway & Transit time of railway to highway (hours) \\
\hline Tianjin & Wait 3-24 hours for ship & Wait 3-48 hours for train & 3 \\
Beijing & N/A & N/A & 3 \\
\hline
\end{tabular}

TABLe 4: Transshipment costs per unit of two transport modes at each demand point (unit: yuan/vehicle $/ \mathrm{km}$ ).

\begin{tabular}{lccc}
\hline$c t_{s h}^{i}$ & Transit costs from road to waterway & Transit costs from waterway to railway & Transit costs from railway to road \\
\hline Tianjin & 0 & 1.2 & 0 \\
Beijing & 0 & 1.2 & 0 \\
\hline
\end{tabular}

TABLE 5: The arrival time limit at each demand point (unit: hours).

\begin{tabular}{lc}
\hline$p p_{i}$ & Transit time (due date) \\
\hline Shanghai to Tianjin & 72 \\
Shanghai to Beijing & 96 \\
Shanghai to Dalian & 120 \\
\hline
\end{tabular}

calculation. In fact, the cost of multimodal transportation is generally the lowest due to its scale effect. Therefore, the result of this study may be contrary to the general theory without considering the scale effect.

Some of the data collected, such as transmit time, are uncertain, so it may lead to slightly inaccurate calculations, such as unit transportation cost, overtime penalty cost, and quantity demand. Therefore, the fluctuation margin of the following sensitivity analysis against various data is about $10 \%$.

There is a huge gap among the three direct transportation modes in terms of both unit transportation cost and transportation time, so the smaller fluctuations do not have an impact on the transportation mode, and the following analysis is mainly against multimodal transportation.

First, the unit transportation cost and transportation time are analyzed. According to the given data in Table 6 and the practical operation, it is found that the unit transportation cost of truck-load is not related to time, but merely to the transportation volume. Therefore, the fluctuation of transportation time does not affect the selection of transportation modes. Thus, the fluctuation of the unit transportation cost is analyzed. There are three sections of transportation and the last two parts are Tianjin-Beijing and Beijing-Dalian sections. The unit transportation cost and transportation time of railway transport have their advantages, and smaller fluctuations will not have an impact on the results. Therefore, this study mainly focuses on the analysis of fluctuations in unit transportation costs from Shanghai to Tianjin. The upward fluctuation of the unit transportation of the railway will not affect the result of choosing cheaper waterway transport. Therefore, this study mainly considers $10 \%$ of the downward fluctuation of railway unit transportation.

The analysis results show that when the unit transportation cost of the railway fluctuates slightly. It is not enough to make up for the cost of water transport, especially the overtime cost, which has no effect on the result. When the unit transportation cost of the railway (e.g., 640 yuan/ vehicle) is close to that of water transportation, when the unit transportation cost is not much higher, the advantage of railway transportation time becomes prominent. Although the cost is still higher than water transport, the higher part is lower than the overtime cost of water transport. Therefore, it has a greater impact on the results. 
TABLE 6: Sensitivity analysis of railway unit transportation cost from Shanghai to Tianjin.

\begin{tabular}{|c|c|c|c|c|c|c|c|}
\hline $\begin{array}{l}\text { Unit transportation } \\
\text { cost (yuan/unit) }\end{array}$ & 690 & 680 & 670 & 650 & 640 & 630 & 620 \\
\hline $\begin{array}{l}\text { Total cost }(10,000 \\
\text { RMB })\end{array}$ & 406.20176 & 406.20176 & 406.20176 & 406.20176 & 403.068 & 398.126 & 393.184 \\
\hline Transportation mode & $\begin{array}{l}\text { Waterway- } \\
\text { railway-railway }\end{array}$ & $\begin{array}{l}\text { Waterway- } \\
\text { railway-railway }\end{array}$ & $\begin{array}{l}\text { Waterway- } \\
\text { railway-railway }\end{array}$ & $\begin{array}{l}\text { Waterway- } \\
\text { railway-railway }\end{array}$ & $\begin{array}{l}\text { Railway- } \\
\text { railway- } \\
\text { railway }\end{array}$ & $\begin{array}{l}\text { Railway- } \\
\text { railway- } \\
\text { railway }\end{array}$ & $\begin{array}{l}\text { Railway- } \\
\text { railway- } \\
\text { railway }\end{array}$ \\
\hline
\end{tabular}

Note. Waterway-railway-railway means the first section is waterway transportation and the last two parts are railway transportation.

Then, $10 \%$ fluctuation in transit and transshipment costs is analyzed. Based on the previous analysis, the possibility of transshipment in Tianjin is relatively high, especially from water transport to railway transport. There is no need to consider transshipment elsewhere. In the previous discussion on the transmit time of 3,12 , and 48 hours, the transportation mode has not changed. As a result, the transshipment cost is the only consideration. Obviously, the reduction in transshipment costs will not affect the results, and the upward fluctuations are mainly considered.

The results demonstrated that the fluctuation of Tianjin's transshipment cost will not affect the change of transportation mode, but the total logistics cost will change proportionally due to the change of unit transshipment costs.

In addition, the overtime penalty cost and the $10 \%$ fluctuation in demand are analyzed. As a consequence, the transportation mode does not change. In this mission, the main situation is that overtime of 1 hour occurred in Beijing. The logistics cost caused by the small fluctuation of the penalty cost is too small for the entire multimodal transportation to affect the entire decision-making. As for demand, the main unit transportation costs and unit transshipment costs are high or low due to the influence of decision-making. Thus, demand fluctuations cannot play a role in the change of transportation modes but can only increase or decrease the total logistics cost in direct proportion to the number of demand fluctuations.

\section{Conclusions}

The above sensitivity analysis shows that the smaller fluctuations have basically no effect on calculating results, and the sensitivity is low. Most of the data fluctuate because the three transportation modes, regardless of the unit transportation cost and transportation time, have a relatively large difference, except for the water transport and railway transport in the Shanghai-Tianjin section. Some data, such as transshipment undergoes a short time against the entire multimodal transportation (such as transshipment), cannot pose a remarkable impact, and the sensitivity is also very low. Or some data, such as transit time data, have little impact on the results: because of the long intermodal transport time and the short transit time, the transit time may not have a greater impact on the overall multimodal transport results, resulting in the low sensitivity. Since the unit price of water transport from Shanghai to Tianjin and railway transport has a great influence on this multimodal transport, the decision-making should take into account the price change of railway transport and waterway transportation.

For the problem of excessively high logistics costs in the process of long-distance transportation of vehicle logistics, a mixed integer programming model is used for calculation, and a vehicle logistics vehicle optimization path model in the context of a soft time window is established to obtain the optimal multimodal transportation that meets the time requirements, which saves costs for enterprises. We select a fixed line and prove the feasibility of the model through simulation calculations on a company's real transportation vehicles. Therefore, for logistics companies, the research results of this article are somewhat significant in reducing energy consumption, offsetting business operating costs, and improving efficiency. At the same time, it has reference value for similar transportation companies.

It should be noted that, for the overtime arrival of vehicles, the automotive OEM (original equipment manufacturer) uses the method to assess the transportation company's monthly KPI to decide whether to punish or not, which is converted into a penalty for calculation in this study.

\section{Data Availability}

The data are available upon request to the author.

\section{Conflicts of Interest}

The author declares no conflicts of interest.

\section{References}

[1] N. M. E. Normasari, V. F. Yu, C. Bachtiyar, and Sukoyo, "A simulated annealing heuristic for the capacitated green vehicle routing problem," Mathematical Problems in Engineering, vol. 2019, no. 2, 18 pages, Article ID 2358258, 2019.

[2] L. Li and H. Fu, "Order allocation problem of vehicle logistics service supply chain considering multiple modes of transportation," Journal of Computer Applications, vol. 39, no. 6, pp. 1836-1841, 2019, (in Chinese).

[3] Y. Hu and S. Yuhong, "Multimodal transportation and route optimization of vehicle logistics," Journal of Transportation Engineering and Information, vol. 7, no. 1, pp. 13-18, 2019, (in Chinese).

[4] Y. Jiang, X. Qi, H. Ren, and Z. Jin, "Automobile logistics routing problem optimization under resource sharing mode," Journal of Highway and Transportation Research and Development, vol. 34, no. 6, pp. 114-121, 2017, (in Chinese). 
[5] J.-F. Cordeau, M. Dell'Amico, S. Falavigna, and M. Iori, "A rolling horizon algorithm for auto-carrier transportation," Transportation Research Part B: Methodological, vol. 76, pp. 68-80, 2015.

[6] Y. Hou, Z. Jia, X. Tian, and W. Fangfang, "Research on the optimization on the vehicle logistics distribution wih soft time windows," Journal of Systems Engineering, vol. 30, no. 2, pp. 240-249, 2015, (in Chinese).

[7] M. Dell'Amico, S. Falavigna, and M. Lori, "Optimization of a real-world auto-carrier transportation problem," Transportation Science, vol. 49, no. 2, pp. 402-419, 2014.

[8] J. Liu and Z. Ma, "Multi-depot open vehicle routing problem with time windows based on vehicle leasing and sharing," Systems Engineering: Theory and Practice, vol. 33, no. 3, pp. 666-675, 2013, (in Chinese).

[9] B. Cheng, Y. Yang, and A. Liu, "Highway transportation route selection optimization based on improved genetic annealing algorithm," Computer Integrated Manufacturing Systems, vol. 19 , no. 4, pp. 879-887, 2013, (in Chinese).

[10] H. Ma, P. Jin, and S. Yang, "Heuristic methods for timedependent vehicle routing problem," Journal of Systems Engineering, vol. 27, no. 2, pp. 256-262, 2012, (in Chinese).

[11] T. Liu, W. Xu, and Q. Wu, "Modeling of multi-vehicle route searching with soft time windows under sudden-onset disaster," Journal of Tongji University:Natural Science, vol. 40, no. 1, pp. 109-115, 2012, (in Chinese).

[12] R. Baldacci, "Recent exact algorithms for solving the vehicle routing problem under capacity and time window constraints," European Journal of OperafionM Research, vol. 6, no. 37, pp. 1-6, 2011.

[13] G. Xiong and W. Yong, "Optimization algorithm of multimodal transportation with time windows and job integration of multi-agent," Journal of System Engineering, vol. 26, no. 3, pp. 379-386, 2011, in Chinese.

[14] S. Ceschia, L. Di Gaspero, and A. Schaerf, "Tabu search techniques for the heterogeneous vehicle routing problem with time windows and carrier-dependent costs," Journal of Scheduling, vol. 14, no. 6, pp. 601 605-615, 2011.

[15] L. Lin, S. Liu, and J. Tang, "Improved ant colony algorithm for solving vehicle touting problem with time window," Control and Decision, vol. 25, no. 9, pp. 1379-1383, 2010, (in Chinese).

[16] M. Jin, S. D. Eksioglu, B. Eksioglu, and H. Wang, "Mode selection for automotive distribution with quantity discounts," Networks and Spatial Economics, vol. 10, no. 1, pp. 1-13, 2010. 